\title{
Speciation and spatial distribution of nitrogen in surface sediments of in Ming Lake
}

\author{
Li Yu ${ }^{1, *}$, Kuang Qi-yu², Din Chao ${ }^{1}$ \\ ${ }^{1}$ Liupanshui Normal University, school of chemical and materials engineering, liupanshui, China 553004 \\ ${ }^{2}$ Scientific research department of Liupanshui Normal University, liupanshui, China 553004
}

\begin{abstract}
To reveal the diverse occurrence forms and spatial distribution characteristics of nitrogen in the surface sediments of Ming Lake, a sequential leaching method was employed to determine the nitrogen in the surface sediments of Ming Lake. The results show that the total Nitrogen (TN) of the surface sediments of Ming Lake are between 383.23 and $3270.38 \mathrm{ug} / \mathrm{g}$, and the spatial distribution is generally shown as southwest $>$ middle $>$ southeast $>$ west of the lake. The results indicate the nutrient level of the whole lake is not very high. However, for some local areas a risk of high eutrophication pollution may exist due to excessive content; the average TTN is $638.77 \mathrm{ug} / \mathrm{g}$ which occupying $36 \%$ of the lake; the spatial distribution is the same with TN; the average (NTN) is $928.61 \mathrm{ug} / \mathrm{g}$ that occupied $61 \%$ of TN. With the exception of SAEF-N, every occurrence form of nitrogen was positive with TOM, indicating that the content and spatial distribution of organic matter in the surface sediments of Minghu Lake are the main controlling factors for the content and spatial distribution characteristics of various forms of nitrogen in the sediments.
\end{abstract}

\section{Introduction}

In recent years, measurements such as harnessing the surrounding environment of lakes, cutting off the import of exogenous pollution into lakes were taken to reduce eutrophication of lakes. This method has achieved good results in the early stage, however, with the passage of time scale, lake water eutrophication again highlighted. The results show that [1-3], as a result of many nonnatural activities, a large number of nitrogen and phosphorus nutrient wastes are collected and deposited in lake sediments through various channels, making the sediments become the "sink" and "source" of the main eutrophic nitrogen and phosphorus salts in lake ecosystems [4-5]. When blocking the influx of exogenous $\mathrm{N}$ and $\mathrm{P}$ nutrients, the endogenous $\mathrm{N}$ and $\mathrm{P}$ salts deposited in the sediments are dissolved into the water again through the concentration gradient formed by the Sediment-Overlying water body in the form of desorption, dissolution, release and diffusion, which aggravates the risk of secondary eutrophication pollution in the lake water body [6-7].

$\mathrm{N}$ is the primary factor limiting the primary viability of lakes. Previous studies [8] indicate that all forms of nitrogen accumulated in sediments can not migrate back to the water body through the Sediment-Overlying water interface to improve the level of $\mathrm{N}$ nutrition in Lake water. Therefore, when evaluating the endogenous nutrient load of lakes, we should not only study and consider the single factor of TN in Lake sediments, but also comprehensively study and analyze the various forms and spatial distribution characteristics of $\mathrm{N}$ in Lake sediments, and put forward effective control schemes. Minghu Lake is an artificial shallow plateau lake [9]. Under the circumstance of cutting off the external pollution sources, there will still be local algae flooding, covering the water body and serious blooms in November to March of next year. In this paper, the surface sediment of Minghu Lake was taken as the research object, and the continuous extraction method of sediment $\mathrm{N}$ proposed by Ma Hongbo et al. [10-11] was used to study the occurrence form and spatial distribution characteristics of $\mathrm{N}$ in Minghu Lake sediment and its correlation with total organic matter (TOM) in sediment. To control the release of endogenous nitrogen in the sediments of Minghu Lake and control the blooms in the water body of Minghu Lake, the corresponding theoretical basis was provided.

\section{Materials and methods}

\subsection{Overview of the research area}

Minghu Lake is located in Liupanshui City, Guizhou Province. Its total area is about $23.1 \mathrm{hm}^{2}$. The lakes are mainly artificial reservoirs and a small number of permanent rivers. It is the source area of Shuicheng Xiangshui River. The structure of the lake area is located in the transition zone from the eastern Yunnan Plateau to the hills in central Guizhou and from the northwestern Guizhou Plateau to the hills in Guangxi. The terrain is 
high in Northwest and low in southeast, inclining from northwest to southeast. Natural precipitation is the main source of water supply in lakes. The precipitation is mostly concentrated in May to October, with an average annual precipitation of $1420.8 \mathrm{~mm}$ [12]. The lake flow generally flows from west to East [13].

\subsection{Sample Collection and Processing}

From November 2018 to January 2019, according to the landform of Minghu Lake and the water function area of the basin, 20 sampling points were arranged in two main entrances, buffer zones, eco-tourism zones, Lake centers and outlets of Minghu Lake (Yaochi and Yixiantian), respectively, using GPS positioning (Fig. 1). Using Petersen mud collector, surface sediments of $0-10 \mathrm{~cm}$ were collected at each point, and three parallel sediments were mixed and packed in bags. The sediments were brought back to the laboratory at $4{ }^{0} \mathrm{C}$ constant box temperature. After freeze-drying, grind through 100 mesh sieve for further analysis.

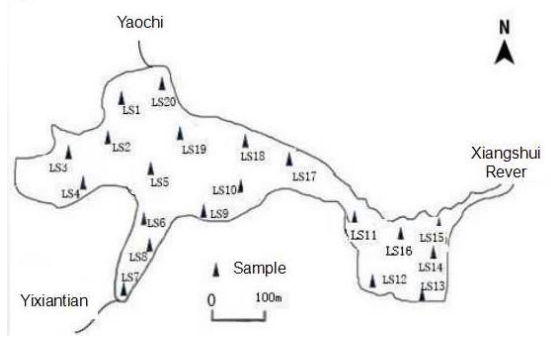

Fig. 1 Sampling sites in Ming Lake

\subsection{Sample Detection and Data Processing}

Sediment samples of $0.5 \mathrm{~g}$ were extracted step by step by step with Ma Hongbo et al. [10-11], using $0.1 \mathrm{~mol} / \mathrm{L} \mathrm{KCl}$, $\mathrm{pH}=5.0 \mathrm{HAc}-\mathrm{NaAc}$ buffer solution, $0.1 \mathrm{~mol} / \mathrm{L} \mathrm{NaOH}$ and alkaline $\mathrm{K}_{2} \mathrm{~S}_{2} \mathrm{O}_{8}$. Four occurrence forms of TTN (convertible nitrogen) in sediments were obtained successively: (1) dissolved with $\mathrm{KCl}$; IEN-N (ionexchangeable nitrogen) WAEN-N (weak acid extractable nitrogen) extracted by HAc-NaAc buffer solution SAEN-N (strong alkali extractable nitrogen) extracted by $\mathrm{NaOH}$ strong alkali solution SOEN-N (strong oxidation extractable nitrogen) extracted by alkaline $\mathrm{K}_{2} \mathrm{~S}_{2} \mathrm{O}_{8}$ strong oxidant solution. The determination method of each index in sediment refers to the Handbook of Sediment Quality Investigation and Assessment [14].

Nitrogen $\left(\mathrm{NH}_{4}{ }^{+}-\mathrm{N}\right)$ in leaching liquor of all levels was determined by Nessler reagent spectrophotometry; Nitrogen $\left(\mathrm{NO}_{3}-\mathrm{N}\right)$ was determined by hydrochloric acidsulfamic acid spectrophotometry; because of the low value of $\mathrm{NO}_{2}-\mathrm{N}$ in this determination, it was neglected; Nitrogen TN was determined by automatic Kjeldahl method; and ToM was determined by potassium dichromate volumetric method. TTN in surface sediments is the sum of its four forms of N. NTN in surface sediments $=$ TN - TTN [11]. The mixed samples at each sampling point were measured three times in parallel. The error range of each measurement result was controlled within $5 \%$. The final experimental data were expressed as average. Excel 2013, Origin 8.0 and SPSS 19.0 software were used to analyze the test data.

\section{Results and analysis}

\subsection{Spatial distribution of TN, TTN and NTN in surface sediments of Minghu Lake}

$\mathrm{TN}$ in sediment is one of the important environmental factors reflecting its nutritional level. $\mathrm{TN}$ of surface sediment samples from 20 sites in Minghu Lake ranged from 593.23 to $3270.38 \mathrm{ug} / \mathrm{g}$, with an average value of $1502.94 \mathrm{ug} / \mathrm{g}$. It is lower than Hongfeng Lake and Baihua Lake (mean 3600 4000ug/g) [15] and Erhai Lake (mean $3537 \mathrm{ug} / \mathrm{g}$ ) [16], slightly higher than Dongting Lake (mean $1371.85 \mathrm{ug} / \mathrm{g}$ ) [6], but the regional content is too high, and there is a high risk of eutrophication pollution of water body. As can be seen from Figure 2, the spatial distribution of $\mathrm{TN}$ in surface sediments of Minghu Lake is quite different, with the maximum value coming out. At present, the sampling point Ls 3 in the southwest of Minghu Lake TN is $3270.38 \mathrm{ug} / \mathrm{g}$, and the minimum value appears at Ls 17 in the northwest of the lake area $\mathrm{TN}$ is $383.23 \mathrm{ug} / \mathrm{g}$. The spatial distribution trend of Ls 3 in the southwest of the lake area (2367.62 $\mathrm{ug} / \mathrm{g})>$ in the middle part $(2095.55 \mathrm{ug} / \mathrm{g})>$ in the southeast part $(1051.96 \mathrm{ug} / \mathrm{g})>$ in the northwest part $(914.08 \mathrm{ug} / \mathrm{g})$. Most of the high-value areas are located in the low-lying detention zones in southwest China, and the low-value areas are mainly concentrated in the higher elevation areas in Northwest China.

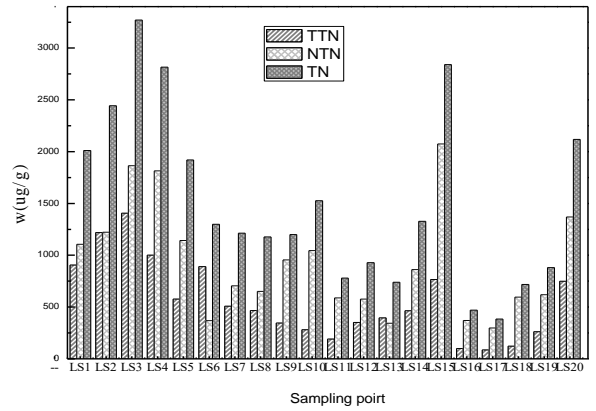

Fig. 2 Distrbution characteristics of TN, TTN and NTN in overlying sediments from Ming Lake

TTN in sediments can directly participate in nitrogen cycling in Lake eco-geochemical system, easily transform and release nitrogen elements absorbed by plankton for photosynthesis, which has an important impact on lake ecological environment [10]. The TTN of surface sediment samples in Minghu Lake ranged from 85.77 to $1406.26 \mathrm{ug} / \mathrm{g}$, with an average value of 554.32 $\mathrm{ug} / \mathrm{g}$. It accounted for $36 \%$ of $\mathrm{TN}$, and the correlation coefficient between TN and TN was 0.888 ( $\mathrm{p}<0.01$ ). There was a significant positive correlation between the maximum and minimum distribution sites and TN distribution sites. The spatial distribution in the lake area is generally in the southwest $(1084.42 \mathrm{ug} / \mathrm{g})>$ the middle $(541.32 \mathrm{ug} / \mathrm{g})>$ the Southeast $(388.76 \mathrm{ug} / \mathrm{g})>$ the Northwest $(263.81 \mathrm{ug} / \mathrm{g})$. The distribution of high and low value areas is consistent with that of $\mathrm{TN}$.

NTN has the most stable chemical properties in real lake sediments and hardly participates in the 
biogeochemical cycle of Sediment-Overlying water body [13]. The NTN of surface sediment samples in Minghu Lake ranged from 297.46 to $2074.94 \mathrm{ug} / \mathrm{g}$, with an average value of $928.61 \mathrm{ug} / \mathrm{g}$. It accounted for $64 \%$ of $\mathrm{TN}$ and the correlation coefficient $\mathrm{R}=0.947$ ( $\mathrm{p}<0.01$ ). The maximum value appeared at Ls15 locus in the center of the lake, and the minimum value appeared at Ls11 locus in the southeast. The spatial distribution trend in the lake area is: central (1420.89 ug/g) $>$ southwest $(1275.19 \mathrm{ug} / \mathrm{g})>$ southeast $(668.92 \mathrm{ug} / \mathrm{g})>$ northwest $(650.23 \mathrm{ug} / \mathrm{g})$. TN accumulates in lake sediments in two forms: transformable TNT and non-transformable NTN. Non-transformed NTN is the predominant form of nitrogen in surface sediments of Minghu Lake. However, due to $\mathrm{TTN} / \mathrm{TN}=0.36$, the transformation activity of endogenous $\mathrm{N}$ in lakes is weak. Therefore, in most of the lake area, the concentration of $\mathrm{p}(\mathrm{TN})<1.0 \mathrm{mg} / \mathrm{L}$ is maintained within the range of type III water.

\subsection{Measurement and Spatial Distribution of TTN in Surface Sediments of Minghu Lake}

TTN accumulated in sediments has four occurrence forms. IEF-N is the most active part of TTN. It is easy to be replaced by other ions in sediments, desorbed, released and diffused into the water body, and directly participates in the life activities of Lake organisms. Figure 3 shows that the IEF-N of surface sediment samples in Minghu Lake ranges from 5.22 to 106.39 $\mathrm{ug} / \mathrm{g}$ with an average value of $52.74 \mathrm{ug} / \mathrm{g}$. The proportion of IEF-N is $10 \%$ of TTN, and the spatial distribution of IEF-N is generally southwest $(89.05 \mathrm{ug} / \mathrm{g})>$ Central $(52.59 \mathrm{ug} / \mathrm{g})>$ Southeast $(47.21 \mathrm{ug} / \mathrm{g})>$ Northwest $(24.23 \mathrm{ug} / \mathrm{g})$. The high value areas are mostly concentrated in the southwest, while the low value areas are mostly concentrated in the northwest. WAEF-N is mainly leachable organic carbonate-bound nitrogen in sediments. WAEF-N in Lake area is between 21.53 $218.64 \mathrm{ug} / \mathrm{g}$, with an average of $112.92 \mathrm{ug} / \mathrm{g}$. Twentyfive percent of TTN was in the south-west (184.65 $\mathrm{ug} / \mathrm{g})>$ the middle $(127.93 \mathrm{ug} / \mathrm{g})>$ the Southeast $(93.52$ $\mathrm{ug} / \mathrm{g})>$ the northwest $(59.34 \mathrm{ug} / \mathrm{g})$. The highest value appeared at Ls4 locus and the lowest value appeared at Ls17 locus. SAEF-N is mainly nitrogen bound to $\mathrm{Fe} / \mathrm{Mn}$ oxides, which is very sensitive to the redox environment of water-sediment system. Once the DO of the system is low and the sediment system is in the state of reduction, the SAEF-N in the sediment will be reduced by desorption and dissolution [11]. The SAEF-N of surface sediment samples in Minghu Lake ranged from 36.24 to $181.60 \mathrm{ug} / \mathrm{g}$, with an average value of $85.54 \mathrm{ug} / \mathrm{g}$. It accounts for $24 \%$ of TTN. The distribution of high and low value areas is consistent with WAEF-N. SOEF-N is mainly deposited in TTN, which combines with macromolecular organic matter or sulfide in sediments. The source of SOEF-N is decomposition of dead aquatic plants in winter under anoxic conditions. SOEF-N in the lake area ranged from 20.86 to $1126.40 \mathrm{ug} / \mathrm{g}$, with an average value of $303.13 \mathrm{ug} / \mathrm{g} .41 \%$ of TTN, the spatial distribution is generally southwest $(735.80 \mathrm{ug} / \mathrm{g}) \quad>$ Central $(232.28 \mathrm{ug} / \mathrm{g})>$ Southeast $(155.31 \mathrm{ug} / \mathrm{g})>$
Northwest $(119.91 \mathrm{ug} / \mathrm{g})$. The maximum appeared at Ls3 locus and the minimum appeared at Ls17 locus.

The contents of four kinds of convertible nitrogen accumulated in surface sediments of Minghu Lake are arranged according to size as follows: IEF-N $<$ SAEF-N $<$ WAEF-N < SOEF-N. The results are consistent with Zhao Haichao's (2013) [11] study on the occurrence forms of convertible nitrogen in sediments of Erhai Lake. Due to the lower IEF-N in surface sediments of Minghu Lake, the total amount of endogenous nitrogen desorption and release in the lake area is not large. However, WAEF-N is relatively high, which is related to the carbonate strata in the geological background of Minghu Lake. A large number of rocks around the lake area are decomposed by weathering [10], and leached into the lake with rainwater. When the lake water $\mathrm{pH}$ maintained between 7.05 and 8.74. A large number of carbonate deposits collect at the water-solid interface, adsorb nitrogen in the water, and then accumulate in the sediment in the form of WAEF-N. When DO in Lake area decreases and is in neutral or weak acidity, WAEF$\mathrm{N}$ in sediment will release and migrate due to carbonate dissolution, resulting in secondary pollution of water body.
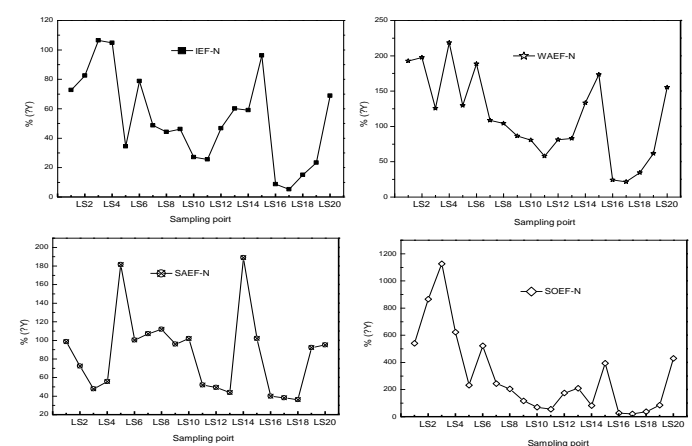

Fig. 3 Distrbution characteristics of quadriform TTN in overlying sediments from Ming Lake

\section{DISCUSSION}

\subsection{Influencing Spatial Distribution of Nitrogen Species in Surface Sediments of Minghu Lake}

The spatial distribution of different forms of nitrogen in surface sediments of Minghu Lake is determined by the combined action of the input of exogenous pollutants, the geological background of the lake and the trend of the water body. At the same time, different forms of nitrogen in sediments will be redistributed by wind blowing, agitation of aquatic animals, and then suspended back to the water for mutual transformation. In surface sediments of Minghu Lake, TN and TTN generally show southwest region, central region, southeast region and northwest region. The main reason is that Minghu Lake is located in a northwest-southeast inclined geological environment with high north and low south. A relatively closed detention area is formed in the southwest of the lake area, and the flow is slow, which is beneficial to a large number of lakes. Nitrogen is stored in sediments in this area. Table 1 shows that TN, TTN 
and NTN in surface sediments are significantly positively correlated with TOM, which is due to the flooding of a large number of farmland and fish ponds during the construction of Minghu Lake, resulting in more organic matter in Lake sediments. With the increase of time scale, the lake "lake-marsh effect" gradually appears. Nitrogen, which is carried by organic matter, will eventually accumulate in surface sediments due to adsorption and sedimentation. The lower TN and TTN in surface sediments in Northwest China may be due to the high topography of the area, and the sediments are mainly composed of large granular sand $(44.64 \%$ $\mathrm{SiO} 2$ ). The high value areas of NTN in surface sediments of Minghu Lake are mostly in the center of the lake. The main reason is that the water level in the center of the lake is slowly exchanged in deep water, and it is difficult to suspend nitrogen in the sediments due to external disturbance, which is accumulated with the mineralization of organic matter.

Table 1 The correlation analysis of nitrogen occurrence forms in the sediments of Ming Lake with TN and TOM content indicators

\begin{tabular}{clllllll}
\hline & TN & TTN & NTN & IEF-N & $\begin{array}{l}\text { WAEF } \\
-\mathrm{N}\end{array}$ & $\begin{array}{l}\text { SAEF- } \\
\text { N }\end{array}$ & $\begin{array}{l}\text { SOEF- } \\
\text { N }\end{array}$ \\
\hline $\begin{array}{c}\text { TO } \\
\text { M }\end{array}$ & $0.743^{* *}$ & $0.814^{* *}$ & $0.624^{* *}$ & $0.760^{* *}$ & $0.640^{* *}$ & -0.207 & $0.841^{* * *}$ \\
TN & 1 & $0.888^{* *}$ & $0.947^{* *}$ & $0.859^{* *}$ & $0.787^{* *}$ & $0.186^{* *}$ & $0.839^{* * *}$ \\
\hline
\end{tabular}

The spatial distribution of TTN with four different occurrence forms is the result of mutual transformation of water-sediment interface under external force and environmental factors. Table 1 shows that IEF-N, WAEF-N and SOEF-N are positively correlated with TOM and TN in surface sediments. The significant positive correlation between IEF-N and TOM is that: (1) the mineralization of organic matter in sediments produces new IEF-N; and (2) the mineralization of organic matter provides a site for IEF-N adsorption. WAEF-N and SOEF-N are significantly positively correlated with TOM, indicating that surface sediments containing a large amount of organic matter make WAEF-N and SOEF-N present high values, and they have very similar diagenetic processes. The spatial distribution of WAEF-N and SOEF-N is influenced by the trend of organic matter distribution in sediments [16]. SAEF-N was negatively correlated with TOM. It may be that the sediments contain a large amount of organic matter, and anaerobic decomposition promotes the release of SAEF-N.

\subsection{Correlation analysis of different TTN forms in surface sediments of Minghu Lake}

Nitrogen forms in sediments can be transformed into each other due to the change of sedimentary environment. IEF-N, WAEF-N and SOEF-N were positively correlated with TN (see Table 2). With the increase of $\mathrm{TN}$ in sediments, it increases. Convertible SOEF-N accounts for $41 \%$ of TTN and $15 \%$ of TN. It is the main component of transformable nitrogen TTN and TN. Therefore, the correlation coefficient $\mathrm{R}=0.841$ (P_0.01) between SOEF-N and TN is extremely significant, and there is an inevitable causal relationship between SOEF$\mathrm{N}$ and TN. There is a very significant positive correlation among IEF-N, WAEF-N and SOEF-N, which indicates that these three forms of nitrogen have similar sedimentary environments, and they can transform each other when the environmental factors of sediment-water interface change.

Table 2: Correlation analysis of different TTN forms in surface sediments of Minghu Lake

\begin{tabular}{ccccc}
\hline & IEF-N & WAEF-N & SAEF-N & SOEF-N \\
\hline IEF-N & 1 & $0.869 * *$ & 0.093 & $0.849 * *$ \\
WAEF-N & $0.869 * *$ & 1 & 0.354 & $0.721^{* *}$ \\
SAEF-N & 0.093 & 0.354 & 1 & -0.095 \\
SOEF-N & $0.849 * *$ & $0.721 * *$ & -0.095 & 1 \\
\hline
\end{tabular}

\section{Conclusion}

(1) The range of TN in surface sediment samples of Minghu Lake ranged from 593.23 to $3270.38 \mathrm{ug} / \mathrm{g}$, with an average value of $1502.94 \mathrm{ug} / \mathrm{g}$. The spatial distribution trend of TN in surface sediments of Minghu Lake was generally southwest > Central > southeast > northwest. Most of the high-value areas are located in the low-lying detention zones in southwest China, and the low-value areas are mainly concentrated in the higher elevation areas in Northwest China. NTN ranged from 85.77 to $1406.26 \mathrm{ug} / \mathrm{g}$, with an average value of 638.77 $\mathrm{ug} / \mathrm{g}$. The spatial distribution is similar to that of TN. NTN ranged from 297.46 to $2074.94 \mathrm{ug} / \mathrm{g}$, with an average of $928.61 \mathrm{ug} / \mathrm{g}$. Non-transformed NTN is the dominant form of nitrogen in surface sediments of Minghu Lake, accounting for $64 \%$ of TN.

(2) The contents and spatial distribution of TT N in the surface sediments of Minghu Lake are different, and the spatial distribution of TTN in the four types of TTN are also quite different, the high value area of SAEF-N mainly concentrated in the middle of the lake, and IEF-N only accounted for $10 \%$ of TTN, which indicated that the release of nitrogen in surface sediments was not high, but because WAEF-N accounted for $25 \%$ of TTN, there was a greater risk of nitrogen release in surface sediments.

(3) TN, TTN, IEF-N, WAEF-N and SOEF-N are positively correlated with TOM, while SAEF-N and TOM are negatively correlated. It is clear that the content and spatial distribution trend of organic matter in lake surface sediments are the main controlling factors for the content and spatial distribution characteristics of nitrogen in sediments. There is a strong correlation between SOEF-N and IEF-N and WAEF-N. SOEF-N in sediments can be transformed into WAEF-N and IEF-N with high biological activity due to the decrease of $\mathrm{pH}$ and DO at the sediment-water interface, which increases the possibility of nitrogen eutrophication in Minghu Lake. Therefore, it is necessary to pay close attention to the change of environmental factors between Minghu Lake and sediments. To prevent and control nitrogen pollution in Lake area. 


\section{Acknowledgement}

The authors thank the joint fund of Guizhou Science and Technology Department (No. 7616 of Qiankehe LH [2015]) for financial support.

\section{References}

1. Evans R D, Empirical evidence of the importance of sediment resuspension in lakes. Hyd., 284, (1994)

2. RAkowska M I, Kup R Yianchyk D, Har Msen J, et al. In situ remediation of contaminated sediments using carbonaceous materials. Environ Toxicol Chem, 31, 4, (2012)

3. [3] Wang Shuhang, Jiang Xia, Zhong Lixiang, et al. Seasonal occurrence characteristics of different forms of nitrogen in Chaohu Lake sediments $[\mathrm{J}]$. Environmental Science, 31, 4, (2010)

4. Herber R.A. Nitrogen cycling in marine ecosystem. FEMS Microbiology Reviews, 23, (1999)

5. Smolders A J P, Lamers L P M, Lucassen Echet, et al. Internal eutrophication-how it works and what to do about it: a review. Chem Ecol, 22,2, (2006)

6. Wang Wenwen, Wang Shuhang, Jiang Xia, et al. Occurrence characteristics and release risk of different forms of nitrogen in Dongting Lake sediments. Env. Sci. Res., 26, 6, (2013)

7. Amit Gross, Claude E, Boyd, C W. Nitrogen transformations and balance in channel catfish ponds. Aquacultural Engineering, 24, (2000)

8. LU X, Song J M, Yuan H M, et al. The potential ecological roles of nitrogen in the surface sediments of the southern Yellow Sea (in China). Acta Ecologica Sinica, 24, 8, (2004).

9. Bao Dazhong, You Guizhi. Geological hazard development characteristics and genesis analysis of Zhongshan District, Liupanshui City, Guizhou. Mineral exploration, 1, 4, (2010)

10. Ma Hongbo, Song Jin Ming, Lu Xiaoxia, et al. Geochemistry, 32, 1, (2003)

11. Zhao Haichao, Wang Shengrui, Jiao Lixin, et al. Spatial and temporal distribution characteristics of different forms of nitrogen in sediments of Erhai Lake. Environmental Science Research, 26, 3, (2013)

12. Chen Jingan, Wang Jingfu, Yu Jia, et al. Reservoir ecological environment characteristics and research prospects in southwestern China. Earth and environment, 45,2, (2017)

13. Jiang Xia, Wang Shuhang. Handbook of Sediment Quality Investigation and Assessment. Beijing: Science Press, 22-33, (2012)

14. Wang Yuchun, Wanguojiang, Yin Qingqing, et al. Occurrence characteristics of total nitrogen, exchangeable nitrogen and fixed nitrogen in sediments of Hongfeng Lake and Baihua Lake. Lake Science, 14, 4, (2002)

15. Wang Shengrui, He Zongjian, Zhao Haichao, et al. Total nitrogen content and ammonia nitrogen release characteristics in surface sediments of Erhai Lake. Environmental Science Research, 26, 3, (2013) 